\title{
Mutual interaction between Dinh An estuary and Tran De estuary, Mekong River, Vietnam
}

\author{
Ngoc Thanh NGUYEN1, Sota NAKAJO², Toshifumi MUKUNOKI ${ }^{3}$ \\ ${ }^{1}$ Doctoral Student, Graduate School of Science and Technology, Kumamoto University \\ (2-39-1 Kurokami, Chuoku, Kumamoto 860-8555, Japan) \\ E-mail:143d9406@st.kumamoto-u.ac.jp \\ ${ }^{2}$ Member of JSCE, Assistant Professor, Graduate School of Science and Technology, Kumamoto University \\ (2-39-1 Kurokami, Chuoku, Kumamoto 860-8555, Japan) \\ E-mail:nakajo@kumamoto-u.ac.jp \\ ${ }^{3}$ Member of JSCE, Associate Professor, Graduate School of Science and Technology, Kumamoto University \\ (2-39-1 Kurokami, Chuoku, Kumamoto 860-8555, Japan) \\ E-mail:mukunoki@kumamoto-u.ac.jp
}

\begin{abstract}
Interaction between estuaries of a pair is tremendously important since evolution of an estuary will significantly impact to other and again. Lack of knowledge about the relation of them could probably result in unexpected consequences to one when implementing certain approaches to exploit, operate, maintain or protect other. The aim of this study is to investigate mutual interaction between Dinh An estuary and Tran De estuary of Mekong River in Vietnam under variations of upstream conditions. River discharge, water level, suspended sediment and salinity concentration were collected in the study area in 2009. Estuarine, Coastal and Ocean Modeling System with Sediment (ECOMSED) was used as an application of three-dimensional numerical model. Then sensitive numerical experiments were performed to figure out response of Dinh An and Tran De estuary to change of upstream discharge rate. We confirmed that redistributed portion of the upstream discharge has high responsibility to mutual interaction of hydrodynamics, salinity intrusion and sediment transport characteristics of both Tran De and Dinh An estuary.
\end{abstract}

Key Words : $\quad$ pair estuaries, Mekong River, sediment transport, saline intrusion, ECOMSED

\section{INTRODUCTION}

Tran De - Dinh An is the biggest estuarine pair of Mekong River. The pair accounts for $45 \%$ of total fresh water of Mekong River discharging to the East Sea ${ }^{1)}$. Dinh An estuary is a unique entrance of main international navigation route connecting Cambodia and Mekong Delta to other nations. Tran De estuary is not important as Dinh An but it assumes certain roles. There is a big fish port located in this estuary, where many fishing vessels docking and fishermen make their business after long period of catching fish on the ocean. In recent decades, due to fast pace of river morphology, small islands at the upstream are developing that could probably make river discharge rate of Dinh An and Tran De change; subsequently, influencing on evolution of two estuaries (Fig. 1).

The objective of this study is to clarify mutual interaction between Dinh An and Tran De estuary under various upstream conditions by employing a three-dimensional numerical model so-called Estuarine, Coastal and Ocean Modeling System with
Sediment (ECOMSED). In this paper, we will show the relative responsibility of upstream discharge rate on hydrodynamics, salinity distribution and sediment transport of these two estuaries.

\section{OBSERVATION DATA}

Fig. 1 shows locations of observation stations in the study area. QDA and QTD are two cross transects of river discharge stations in Dinh An and Tran De estuary respectively. Solid squares are locations of water level stations, suspended sediment concentration (SSC) stations are symbolized by solid circles. Hourly river discharge and water level were simultaneously measured at both QDA and QTD in 15 days and nights, from $9 \mathrm{am}$ September $15^{\text {th }} 2009$ to 8 am September $30^{\text {th }} 2009$ in high-flow season by using RD Instrument Acoustic Doppler Current Profiler (ADCP) $600 \mathrm{~Hz}$ and measures. SSC was collected in the same period with river discharge, each day 2 samples were taken at depth of $20 \mathrm{~cm}$ under the 

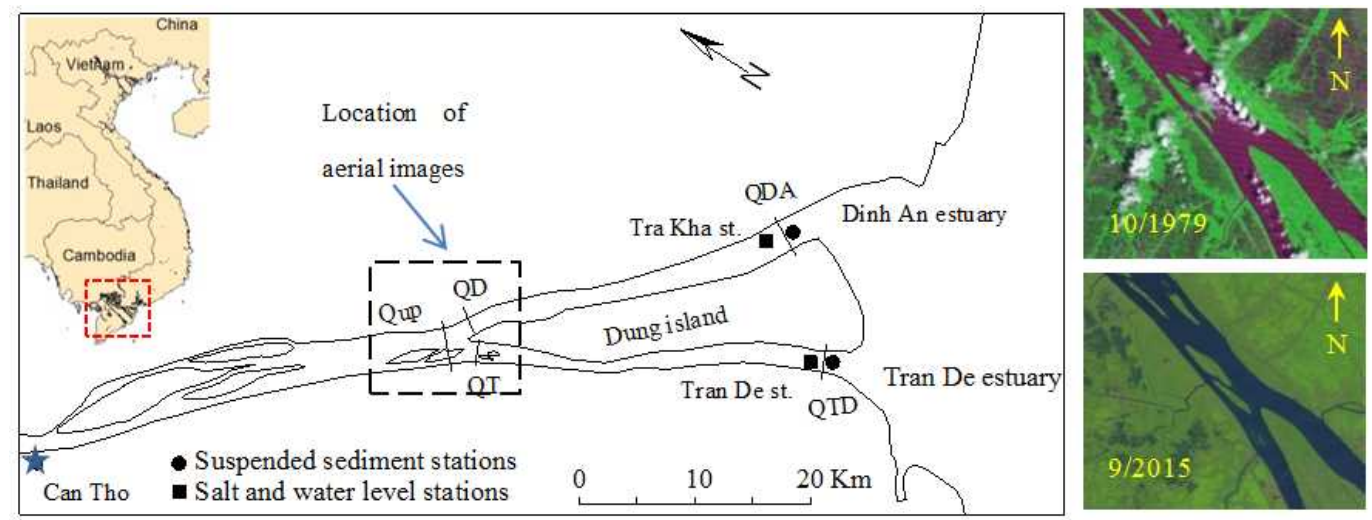

Fig. 1 Map of study area, locations of observation stations and historical aerial images of upstream area

water surface at $7 \mathrm{am}$ and $1 \mathrm{pm}$. Tra Kha (at Dinh An estuary) and Tran De (at Tran De estuary) also marked as solid square signs in Fig. 1 are two national water quality stations. Such stations only work in several months in low-flow season (from November to next-year April) to measure surface salinity concentration. In high-flow season (from May to October), water in the river is fresh water so they are not necessary to operate. In general, salinity concentration is collected every three hours in February; from March to April the data is snippy collected depending on water intake plan of cultivation fields.

\section{NUMERICAL MODEL}

A three-dimensional numerical model ECOMSED was used in this study. ECOMSED is open-source code distributed by HydroQual, Inc ${ }^{2}$. The model uses finite difference method with orthogonal curvilinear grid approach. ECOMSED comprises of hydrodynamics, surface wave, sediment transport and water quality module. It has been widely applied within oceanographic, coastal and estuarine environments spheres.

\section{(1) Hydrodynamics governing equations}

The model is based on the solution of the threedimensional incompressible Reynolds equations, subjects to the assumptions of Boussinesq and of hydrostatic pressure:

$$
\begin{gathered}
\frac{\partial U}{\partial x}+\frac{\partial V}{\partial y}+\frac{\partial W}{\partial z}=0 \\
\frac{\partial U}{\partial t}+U \frac{\partial U}{\partial x}+V \frac{\partial U}{\partial y}+W \frac{\partial U}{\partial z}=f V-\frac{1}{\rho_{0}} \frac{\partial P}{\partial x}+\frac{\partial}{\partial z}\left(K_{M} \frac{\partial U}{\partial z}\right) \\
+\frac{\partial}{\partial x}\left(2 A_{M} \frac{\partial U}{\partial x}\right)+\frac{\partial}{\partial y}\left(A_{M}\left(\frac{\partial U}{\partial y}+\frac{\partial V}{\partial x}\right)\right) \\
\frac{\partial V}{\partial t}+U \frac{\partial V}{\partial x}+V \frac{\partial V}{\partial y}+W \frac{\partial V}{\partial z}=-f U-\frac{1}{\rho_{0}} \frac{\partial P}{\partial y}+\frac{\partial}{\partial z}\left(K_{M} \frac{\partial V}{\partial z}\right) \\
+\frac{\partial}{\partial x}\left(2 A_{M} \frac{\partial V}{\partial y}\right)+\frac{\partial}{\partial x}\left(A_{M}\left(\frac{\partial U}{\partial y}+\frac{\partial V}{\partial x}\right)\right)
\end{gathered}
$$

$$
\rho g=-\frac{P}{\partial z}
$$

where $x, y$ and $z$ are the Cartesian co-ordinates; $U, V$ and $W$ are the velocity components in the $\mathrm{x}, \mathrm{y}$ and $\mathrm{z}$ direction; $f=2 \Omega \sin \phi$ is the Coriolis parameter $(\Omega$ is the angular rate of revolution and $\phi$ is the geographic latitude); $g$ is the gravitational acceleration; $\rho$ is the density of water; $\rho_{0}$ is the reference density of water; $P$ is the atmospheric pressure; $K_{M}$ and $A_{M}$ are vertical eddy diffusivity of turbulent momentum mixing and horizontal eddy viscosity respectively.

Temperature and salinity conservation equations:

$$
\begin{aligned}
& \frac{\partial T}{\partial t}+U \frac{\partial T}{\partial x}+V \frac{\partial T}{\partial y}+W \frac{\partial T}{\partial z}=\frac{\partial}{\partial z}\left(K_{H} \frac{\partial T}{\partial z}\right) \\
& +\frac{\partial}{\partial x}\left(A_{H} \frac{\partial T}{\partial x}\right)+\frac{\partial}{\partial y}\left(A_{H} \frac{\partial T}{\partial y}\right) \\
& \frac{\partial S}{\partial t}+U \frac{\partial S}{\partial x}+V \frac{\partial S}{\partial y}+W \frac{\partial S}{\partial z}=\frac{\partial}{\partial z}\left(K_{H} \frac{\partial S}{\partial z}\right) \\
& +\frac{\partial}{\partial x}\left(A_{H} \frac{\partial S}{\partial x}\right)+\frac{\partial}{\partial y}\left(A_{H} \frac{\partial S}{\partial y}\right)
\end{aligned}
$$

where $S$ is salinity (psu); $T$ is temperature $\left({ }^{\circ} \mathrm{C}\right) ; K_{H}$ is the vertical eddy diffusivity for turbulent mixing of heat and salt; and $A_{H}$ is the horizontal diffusion coefficient.

\section{(2) Sediment transport equation}

Sediment transport is based on the advection dispersion calculation in hydrodynamics model:

$$
\begin{aligned}
& \frac{\partial C}{\partial t}+\frac{\partial U C}{\partial x}+\frac{\partial V C}{\partial y}+\frac{\partial\left(\mathrm{W}-\mathrm{W}_{S}\right) C}{\partial z}=\frac{\partial}{\partial x}\left(A_{H} \frac{\partial C}{\partial x}\right) \\
& +\frac{\partial}{\partial y}\left(A_{H} \frac{\partial C}{\partial y}\right)+\frac{\partial}{\partial z}\left(K_{H} \frac{\partial C}{\partial z}\right)
\end{aligned}
$$

where $C$ is suspended sediment concentration (mg $\left.1^{-1}\right) ; W_{S}$ is settling velocity of the cohesive sediment $\left(\mathrm{m} \mathrm{s}^{-1}\right)$.

\section{MODEL SETUP}

\section{(1) Domains, grids and boundary conditions}

Nested ECOMSED model of study area consists of two different scale models. Fig. 2 sketches domain of 


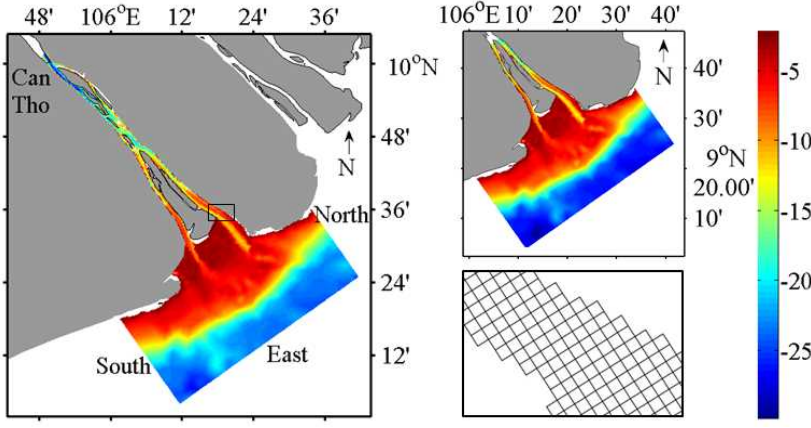

Fig. 2 Bathymetry of large model (left), small model (top right) and a part of the grid (bottom right) of study area; unit: $m$

each model and their grid structure. Two models have same offshore boundaries so-called North, South and East. Upstream boundary of the large model is Can Tho station, and those of the small model are head of Dung island, lower location of division point. The grids of the models have $400 \times 250$ and 250x250 horizontal grid cells respectively. Two models have same grid structure with horizontal grid size of $270 \times 270 \mathrm{~m}$ and 11 vertical layers in sigma coordinate. Bathymetry data was collected from many sources. River bathymetry was obtained from previous projects conducted by Southern Institute of Water Resources Research, Vietnam (SIWRR) (unpublished). Offshore bathymetry is the 30-s Global Bathymetry and Elevation Data SRTM30 PLUS ${ }^{3)}$. Such data was smoothed and interpolated in each grid cell of the grids.

The large model used hourly river discharge, temperature and SSC at Can Tho observation station for river boundary. Saline intrusion is not reached therefore 0 psu was always chosen for salinity concentration at this boundary in every simulation. Three offshore boundaries used 6 tidal harmonic constants of S2, M2, N2, K1, P1 and $\mathrm{O} 1$ constituents. Such constituents were extracted from Global Inverse Solution 7.2 of global ocean tides OSU TOPEX/Poseidon model ${ }^{4}{ }^{4}$. Temperature and salinity data of offshore boundaries and initial condition were taken from HYCOM/NCODA ${ }^{5}$. Wind direction and magnitude of Vung Tau observation station were used as wind forcing for all domain in simulation period. The result of the large model was then used as upstream boundary conditions for the small one.

\section{(2) Model parameters}

The internal time step of simulations was $40 \mathrm{~s}$. The Manning number and roughness height of bed of all domains were 0.028 and $0.001 \mathrm{~m}$ respectively. The horizontal mixing constant of Smagorinsky closure model was $\mathrm{C}_{\mathrm{S}}=0.5$. The vertical eddy diffusivity was adopted from Mellor and Yamada turbulence closure model level 2.5 with background mixing constant was $10^{-4} \mathrm{~m}^{2} \mathrm{~s}^{-1}$. In sediment transport model, target of simulation was only cohesive sediment class. The deposition rate was calculated by using formulation of Krone ${ }^{6}$. Then averaged density of bed was $500 \mathrm{~kg}$ $\mathrm{m}^{-3}$, the settling velocity of sediment was $2.5 \times 10^{-4} \mathrm{~m}$ $\mathrm{s}^{-1}$, the critical shear stresses for erosion and deposition were 1.0 dynes $\mathrm{cm}^{-2}$. Wave parameters used in determining wave-induced bottom shear stress were computed by formulas of Donelan ${ }^{7)}$.

\section{(3) Validation of numerical model}

Model was validated with observed salinity concentration of Tra Kha and Tran De stations in February 2009, river discharge and SSC of QDA and QTD stations in September 2009. Fig. 3, Fig. 4 and Fig. 5 show results of validation of the models. It can be seen that simulated result of discharge well agreed with observed data. Simulated salinity and SSC are although imperceptibly diverged from observed data,

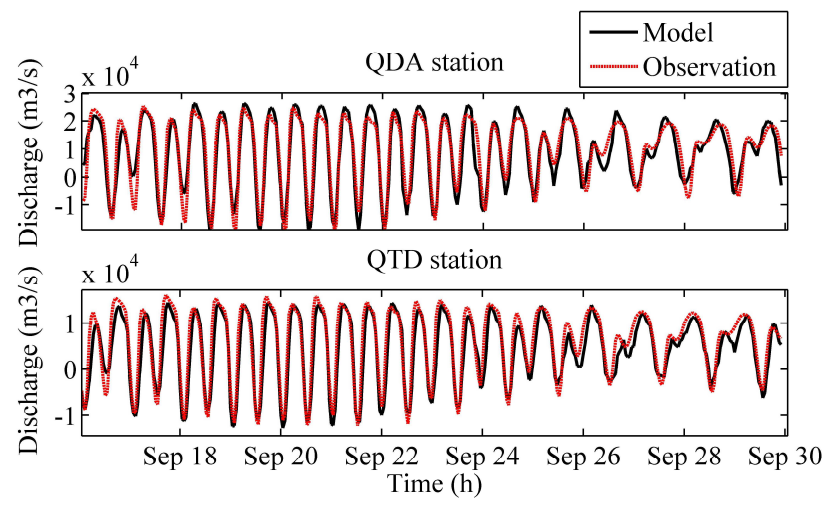

Fig. 3 Comparison of observed and simulated river discharge at QDA (Dinh An estuary) and QTD (Tran De estuary)
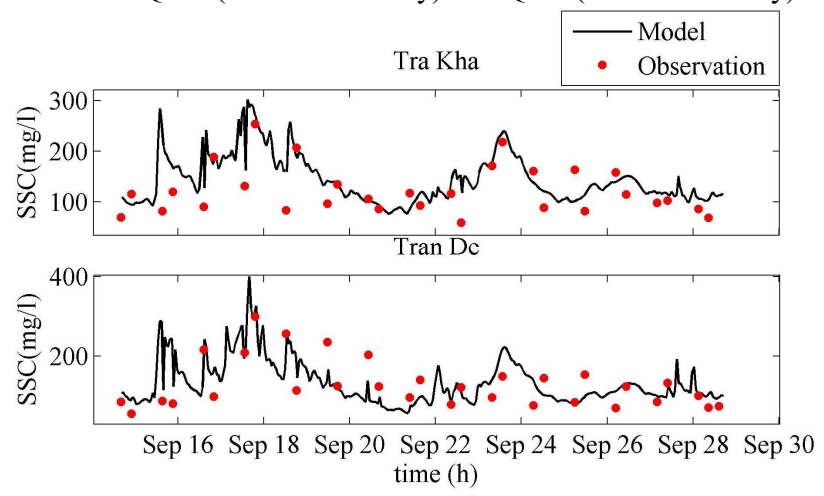

Fig. 4 Comparison of observed and simulated SSC at depth of $20 \mathrm{~cm}$ under water surface at Tra Kha and Tran De
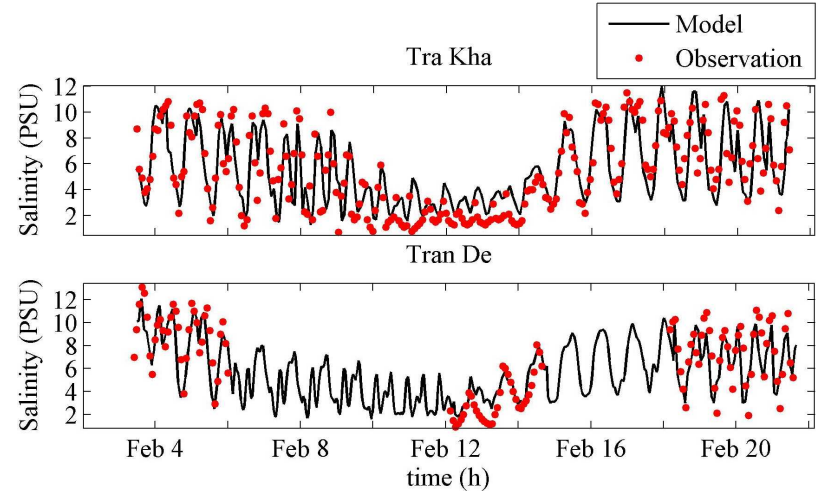

Fig. 5 Comparison of observed and simulated surface salinity concentration at Tra Kha and Tran De 
Table. 1 Results of model validation

\begin{tabular}{lccc}
\hline \multirow{2}{*}{ Constituent } & \multicolumn{2}{c}{ Error index } & \multirow{2}{*}{$\begin{array}{c}\text { Performance } \\
\text { rating }\end{array}$} \\
\cline { 2 - 3 } & NSE & RSR & Very good \\
\hline QDA & 0.875 & 0.354 & Very good \\
QTD & 0.816 & 0.429 & Satisfactory \\
SSC Tra Kha & 0.588 & 0.642 & Satisfactory \\
SSC Tran De & 0.659 & 0.584 & Satisf \\
Salt Tra Kha & 0.613 & 0.622 & Satisfactory \\
Salt Tran De & 0.692 & 0.555 & Satisfactory \\
\hline
\end{tabular}

the phases and peaks are nearly equal. Nash - Sutcliffe efficiency (NSE) and RMSE - observations standard deviation ratio (RSR) indexes ${ }^{5)}$ indicate well performed model in all calculations (Table 1).

\section{RESULTS AND DISCUSSION}

\section{(1) Relations of hydrodynamics and salinity}

Fig. 6 demonstrates discharge rate of Tran De and Dinh An at cross transect QT and QD in Fig. 1. The rate depends on the value of upstream discharge before the division point. Dinh An accounts for $57.43 \%, 66.57 \%, 68.37 \%$ and $68.59 \%$ of the upstream discharge (Qup) corresponding to range of $0-7000 \mathrm{~m}^{3} / \mathrm{s}, 7000-14000 \mathrm{~m}^{3} / \mathrm{s}, 14000-21000 \mathrm{~m}^{3} / \mathrm{s}$ and $21000-28000 \mathrm{~m}^{3} / \mathrm{s}$ respectively. It is obvious that discharge rate is significantly prone to Dinh An when the range of upstream discharge is large. The averaged values for Dinh An and Tran De branches in 2009 are $65.24 \%$ and $34.76 \%$ of upstream discharge.

Fig. 7 shows correlation of discharge at QD and QT; and Fig. 8 presents correlation of salinity concentration at Tra Kha and Tran De station. Although QD and QT have clearly linear relation with $\mathrm{R}^{2}=0.98$, it is hard to find out the same situation in salinity concentration. Generally speaking, salinity concen-
Table 2. Numerical experiments of upstream river discharge

\begin{tabular}{cccc}
\hline \multirow{2}{*}{ No } & $\begin{array}{c}\text { Experiment } \\
\text { case }\end{array}$ & \multicolumn{2}{c}{ Upstream river discharge division } \\
\cline { 3 - 4 } & E1 & Tran De estuary & Dinh An estuary \\
\hline 1 & QT & QD \\
2 & E2 & QT $-5 \%$ Qup & QD $+5 \%$ Qup \\
3 & E3 & QT $-10 \%$ Qup & QD $+10 \%$ Qup \\
4 & E4 & QT $+5 \%$ Qup & QD $-5 \%$ Qup \\
5 & E5 & QT $+10 \%$ Qup & QD $-10 \%$ Qup \\
\hline
\end{tabular}

tration at Tran De is slightly greater than at Tra Kha. This result may be caused that not only discharge rate but also tide variation is governing salinity distribution of these estuaries.

\section{(2) Response of downstream to sensitive change of upstream discharge rate}

To investigate the effect of upstream discharge rate on interaction of hydrodynamics, saline intrusion and sediment transport between Dinh An and Tran De, a series of numerical experiments were simulated for 5 cases of the discharge rate as shown in Table 2. The period of simulations is one month of Feb. 2009. From experiment E2 to E5, all offshore boundary conditions were kept same as actual case E1, and river boundaries were controlled.

As shown in Fig. 9, averagely vertical velocity at QDA and QTD is sensitively subject to variation of discharge rate. When the rate of upstream discharge has bias toward Dinh An (E2 and E3), velocity magnitude at this estuary is raised; and then, velocity magnitude at Tran De is declined. This trend is to oppose in E4 and E5. The rate of increase/decrease of the velocity magnitude is proportional with added/subtracted amount of upstream water discharge. Changing velocity amplitude of Tran De seems greater than Dinh An in all experiment cases. Fundamentally, velocity, erosion and deposition in an

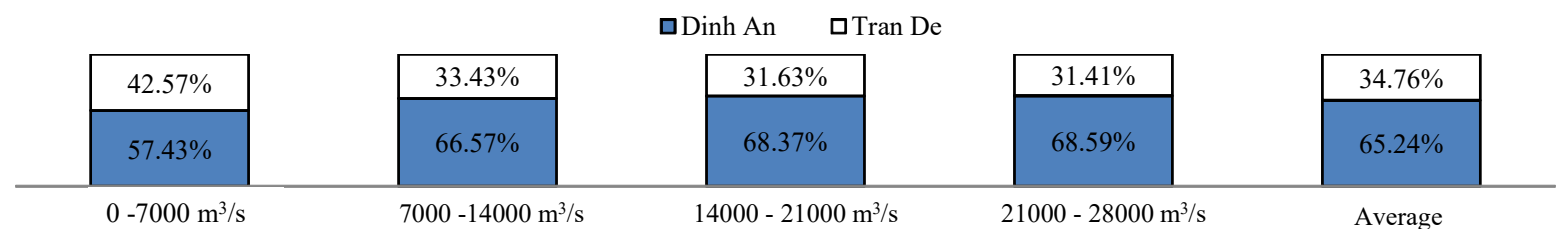

Fig. 6 Discharge rates of Tran De and Dinh An corresponding to various range of upstream discharge

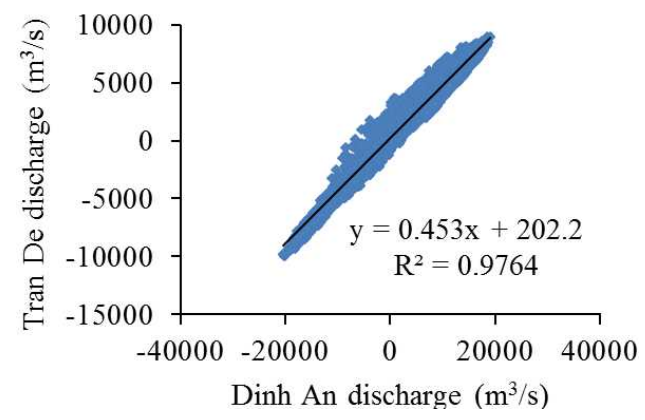

Fig. 7 Correlation of Dinh An and Tran De discharge in 2009

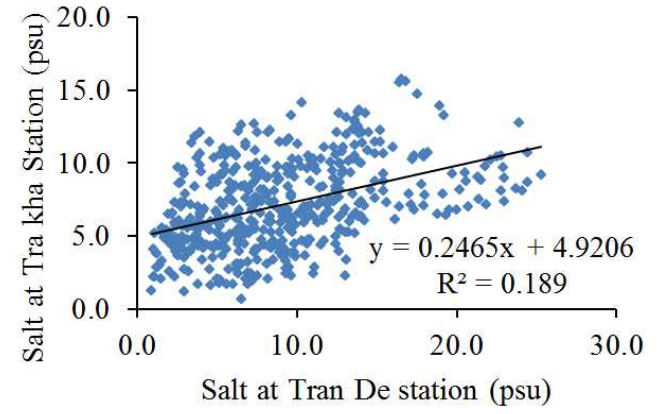

Fig. 8 Correlation of Dinh An and Tran De salinitv in 2009 

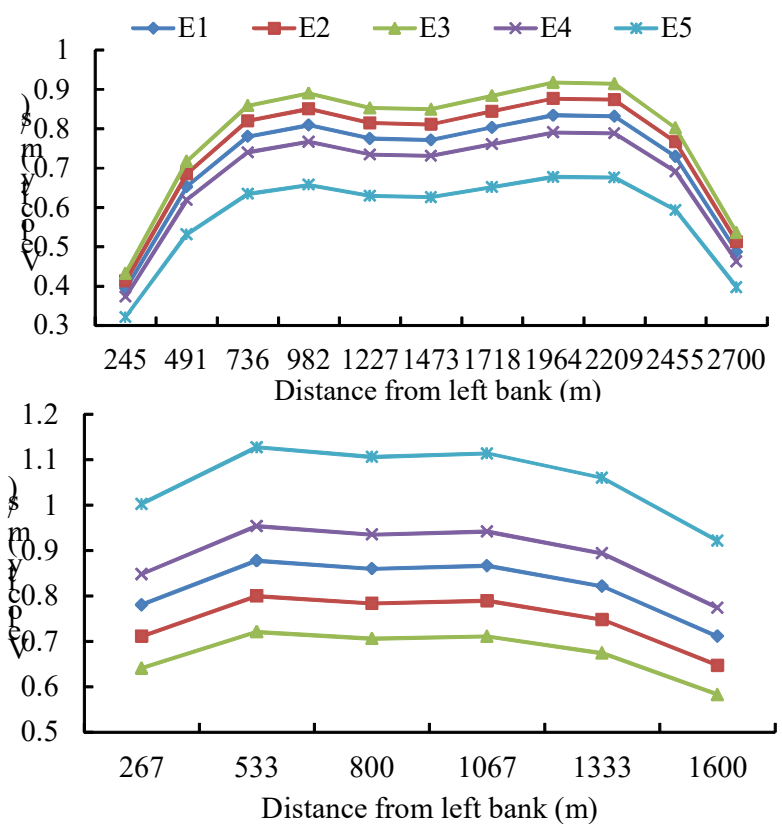

Fig. 9 Averaged value of simulated vertical velocity of experiments at QDA (top) and QTD (bottom) station in flood tide at 2 pm Feb $7^{\text {th }} 2009$

open channel have close relationship. St-Onge et al proved that erosion is accelerated when velocity of flow is intensified, low velocity makes favorable condition for suspended sediment to settle down ${ }^{9)}$.

Salinity concentration at downstream of each branch significantly shifts in experiments which have large change of upstream discharge. Besides, the shifting value is not stable during simulation period. In experiment E3, the discharge at Dinh An is risen, it makes salinity concentration in this estuary reduce maximum of $5.4 \mathrm{psu}$ at Tra Kha and increase the same amount at Tran De when compared with experiment E1. On the contrary, in experiment E5, salinity concentration in Tran De and Tra Kha drops and heightens maximum of 5.8 psu and 3.8 psu respectively. In addition, the results reveal that Tran De is more sensitive with change of discharge than Dinh An (Fig. 10 and Fig. 11).

SSC in Dinh An and Tran De mouth is proportional with changing rate of upstream discharge and velocity magnitude but has inverse relation with salinity concentration. Fig. 12 shows time series of
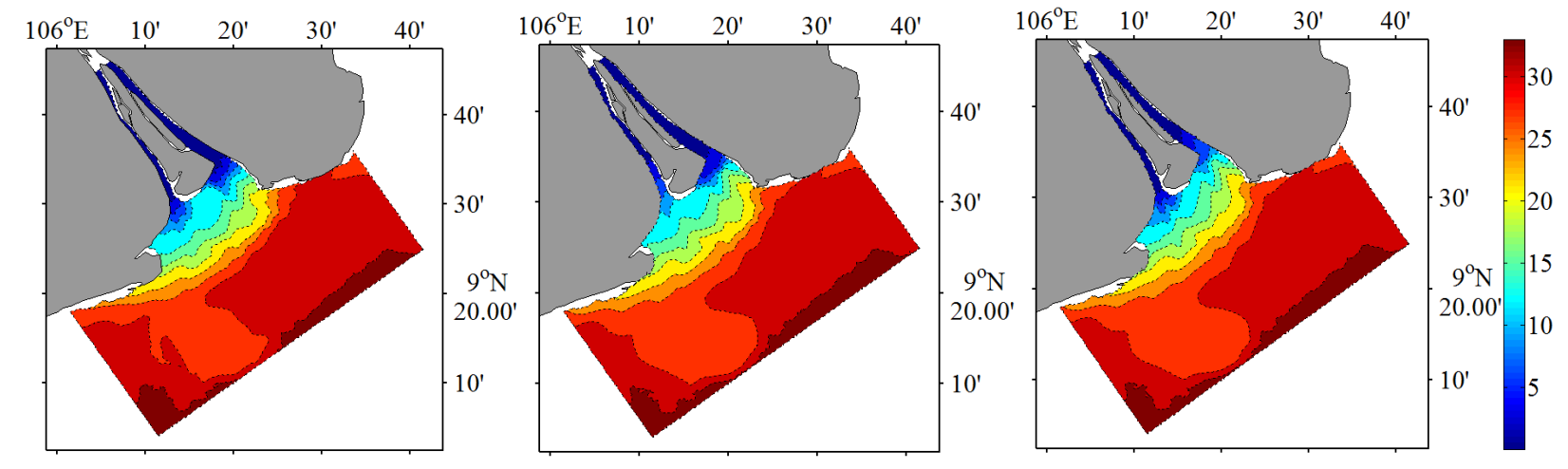

Fig. 11 Modeled salinity distribution of E1 (left), E3 (center) and E5 (right) in flood tide, at 12 pm Feb $7^{\text {th }} 2009$ (unit: PSU)

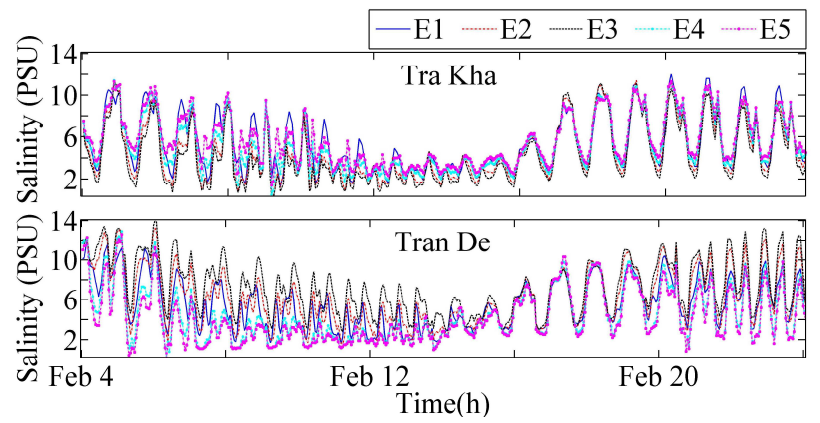

Fig. 10 Comparison of simulated salinity concentration of all experiments at Tra Kha and Tran De in Feb 2009

surface SSC in experiment E1, E3 and E5 at Dinh An and Tran De station. Supplemented or lost amount of upstream river discharge in each branch makes increase or decrease in SSC at vicinity of the mouths (like at Dinh An and Tran De station). Mechanism of such phenomena is to suppose that when the upstream discharge of a branch is gained, it encourages erosion of river bank and river bed in this branch due to strengthened velocity. Subsequently, SSC in water column is higher than in the actual condition. Such amount of SSC is then transported to the mouth; under condition of estuarine circulation, it deposits there $^{10)}$ (corresponding to Dinh An branch in E2 and E3, Tran De branch in E4 and E5). In contrast, if upstream discharge of a branch is smaller than in the actual case, sediment is easy to settle down because velocity intensity is not great enough to carry them out. Therefore, suspended sediment is partly deposited at upstream river part of this branch before flowing to the ocean and it makes SSC in water column near the mouth smaller than actual condition (associating with Dinh An branch in E4 and E5, Tran De branch in E2 and E3). As the result of above sediment dynamics, morphology of estuaries is subject to change. Fig. 13 and Fig. 14 show bed thickness change in experiment E1 as well as differences in bed thickness change between experiment E1 with E3 and E1 with E5 respectively; in which, positive value is deposition and negative one is erosion. When comparing morphology of experiment cases with real condition of Feb. 2009, Dinh An branch is more eroded in river part along with more deposited by 


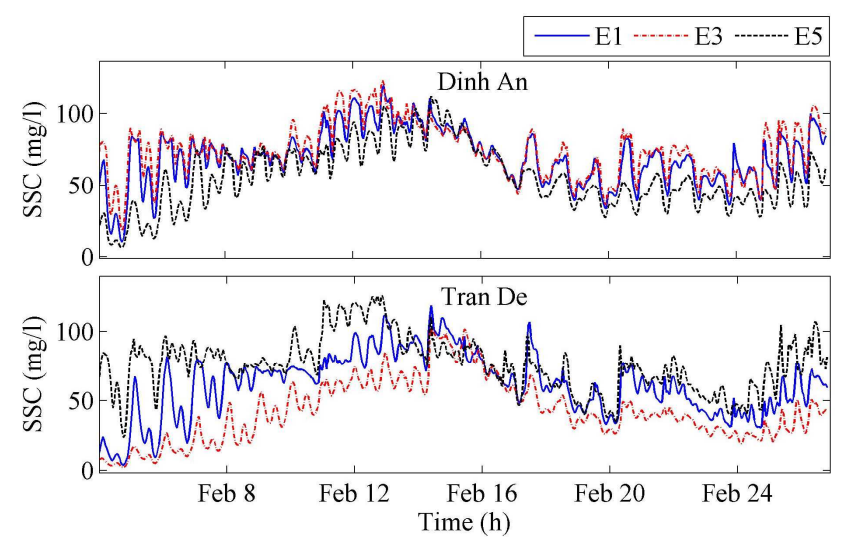

Fig. 12 Comparison of simulated surface SSC in experiment E1, E3 and E5 at Dinh An (top) and Tran De (bottom) station

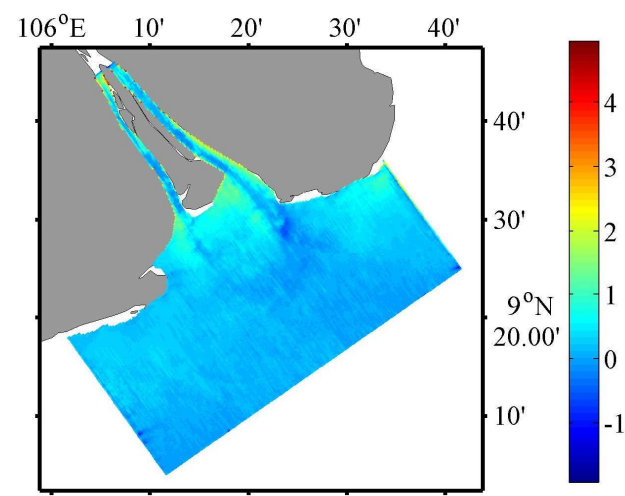

Fig. 13 Bed thickness change in experiment E1; (unit: cm)

sediment near the mouth in experiment E3. In the same time, sediment deposition exceeds in river part of Tran De and more erosion is found at the mouth. The results are opposite in experiment E5 when Tran De discharge is increased. Results of experiment E2 and E4 (not shown) are similar to E3 and E5 respectively but the degree of change is smaller.

\section{CONCLUSIONS}

We applied ECOMSED model to simulate comprehensively mutual interaction of Dinh An-Tran De estuary pair of Mekong River under circumstance of upstream river discharge variation. The model outputs were compared with observed data and shown a good agreement. Simulations of one month of Feb 2009 predicted that current velocity and SSC in the river mouths are roughly proportional to amount of added/deducted upstream river discharge, salinity intrusion of each estuary is remarkably declined when fresh water is inclined to such estuary. Erosion and deposition of sediment are also reallocated by the discharge rate induced intensified/weakened velocity. Further study should simulate in longer term to see seasonal effects on evolution of these estuaries.

\section{REFERENCES}

1) Thanh, L.T.: Morphological processes of the Tien River Estuaries, Mekong River, Vietnam, PhD. Dissertation,
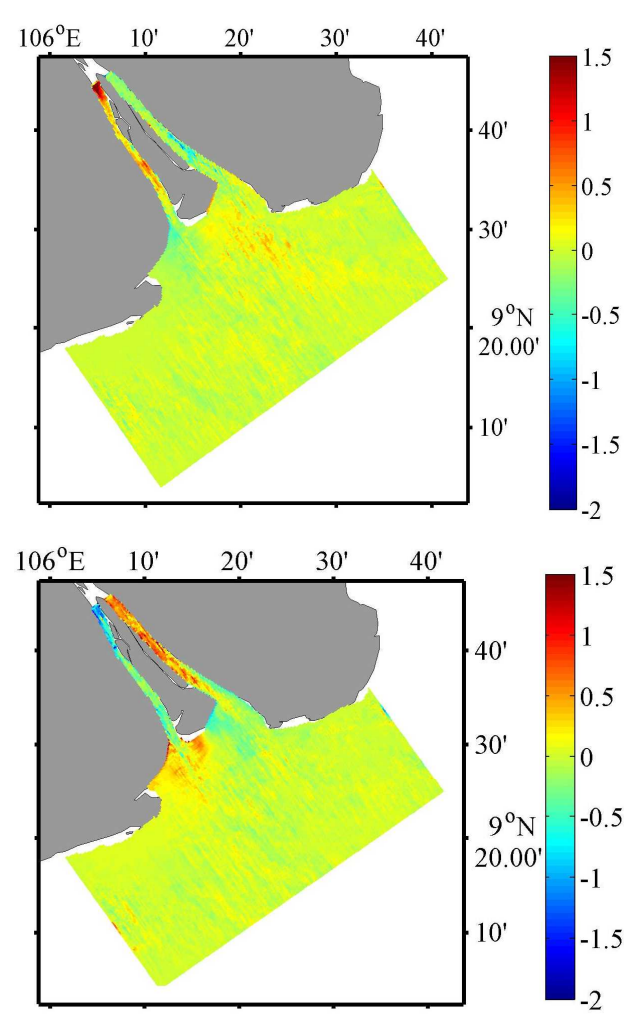

Fig. 14 Difference of thickness change between E3-E1 (top) and E5-E1 (bottom); (unit: $\mathrm{cm}$ )

$141 \mathrm{p}, 2012$.

2) Blumberg, A.F. A primer for ECOMSED: User manual version 1.3, HydroQual Inc. Technical report, 188p.

3) Becker, J.J., Sandwell, D.T, Smith, W.H.F., Braud, J., Binder, B., Depner, J., Fabre, D., Factor, J., Ingalls, S., Kim, S.H., Ladner, R., Marks, K., Nelson, S., Pharaoh, A., Trimmer, R., Von Rosenberg, J., Wallace, G. and Weatherall, P.: Global bathymetry and elevation data at 30 arc seconds resolution: SRTM30_PLUS, Marine Geodesy, Vol 4, pp.355-371, 2009

4) Egbert, G.D., Bennett, A.F. and Foreman, M.G.G: TOPEX/ POSEIDON tide estimated using a global inverse mode, Journal of Geophysical Research, pp 24821-24852, 1994.

5) Chassignet, E.P., Hurlburt, H.E., Smedstad, O.M., Halliwell, G.R., Hogan, P.J., Wallcraft, A.J., Baraille, R. and Bleck, R.: The HYCOM (HYbrid Coordinate Ocean Model) data assimilative system, Journal of Marine Systems, Vol 65, pp 60-83, 2007.

6) Krone, R.B.: Flume studies of the transport of estuarial shoaling processes, Final report, 110p, 1962.

7) Donelan, M.A.: A simple numerical for wave and wind shear stress application, Report, National Water Research institute, Burlington, Ontario, Canada, 28 pp.,1977.

8) Moriasi, D. N., Arnold, J. G., Van Liew M.W., Bingner, R.L., Harmel R.D., Veith T.L.: Model evaluation guidelines for systematic quantification of accuracy in watershed simulations, American Society of Agricultural and Biological Engineers, Vol. 50, No. 3, pp. 885-900, 2007.

9) St-Onge, P., Miron G.: Effects of current speed, shell length and type of sediment on the erosion and transport of juvenile softshell clams (Mya arenaria), Journal of Experimental Marine Biology and Ecology, Vol.349, pp.12-26, 2007.

10) Nguyen, N.T., Nakajo, S., Mukunoki, T.: Effects of current on sediment transport at Dinh An estuary, Mekong River, Vietnam, Journal of Japan Society of Civil Engineers, Ser. B3 (Ocean Engineering), Vol. 71, No. 2, pp. I_790-I_795, 2015.

(Received February 4, 2016) 